\title{
The Lazarus phenomenon
}

\author{
Vedamurthy Adhiyaman ${ }^{1} \quad$ Sonja Adhiyaman ${ }^{2} \quad$ Radha Sundaram $^{3}$
}

J R Soc Med 2007; 100:552-557

\section{SUMMARY}

Even though Lazarus phenomenon is rare, it is probably under reported. There is no doubt that Lazarus phenomenon is a reality but so far the scientific explanations have been inadequate. So far the only plausible explanation at least in some cases is auto-PEEP and impaired venous return. In patients with PEA or asystole, dynamic hyperinflation should considered as a cause and a short period of apnoea (30-60 seconds) should be tried before stopping resuscitation. Since ROSC occurred within 10 minutes in most cases, patients should be passively monitored for at least 10 minutes after the cessation of CPR before confirming death.

\section{DEFINITION}

The Lazarus phenomenon is described as delayed return of spontaneous circulation (ROSC) after cessation of cardiopulmonary resuscitation (CPR). This was first reported in the medical literature in 1982, and the term Lazarus phenomenon was first used by Bray in 1993.1,2 The term was coined from the story of Lazarus, who was resurrected by Christ four days after his death.

\section{METHODS}

\section{Literature Review}

We searched Medline, Pubmed and Google Scholar using the words 'Lazarus phenomenon', 'cardiopulmonary resuscitation' and 'spontaneous return of circulation'. Even though we retrieved more articles from Google Scholar than Medline or Pubmed, we had to screen a large number of articles (more than 14,000) to select the appropriate ones. We scrutinized all the articles to identify cases where cessation of CPR was followed by spontaneous return of circulation.

So far 38 cases of delayed ROSC have been published in the medical literature. ${ }^{1-28}$ The majority of the articles appeared in the anaesthetic and intensive care journals. Cases described include both in-hospital and out-of-hospital

${ }^{1}$ Consultant Geriatrician, Department of Geriatric Medicine, Glan Clwyd District Hospital, Rhyl, Denbighshire LL18 5UJ, UK

${ }^{2}$ General Practitioner, The Laurels, 73 Church Street, Flint, Flintshire CH6 5AF, UK

${ }^{3} \mathrm{SpR}$ in Anaesthetics and Intensive Care Medicine, Intensive Care Unit, Western Infirmary, Dumbarton Road, Glasgow G11 6NT, UK

Correspondence to: V Adhiyaman arrests. We collected information on diagnoses at the time of arrest, duration of CPR, cardiac rhythm when CPR was stopped and time taken for ROSC, and the final outcome (Table 1).

\section{Diagnoses at the time of cardiac arrest}

Of the 38 cases described, 13 had myocardial infarction and eight had obstructive airways disease. Other diagnoses include ruptured abdominal aortic aneurysm, pulmonary artery rupture, gastrointestinal haemorrhage, hyperkalaemia due to renal failure, trauma, digoxin toxicity, sepsis and overdose with opiates and cocaine.

\section{Resuscitation details}

The duration of CPR ranged from 6-75 minutes, with an average duration of 27 minutes. The duration of CPR was not documented in seven patients. When CPR was stopped, 23 patients were in asystole, 12 were in pulseless electrical activity and one was in ventricular fibrillation, and the rhythm was not known in two patients (not mentioned in the reports).

\section{Time to return of spontaneous circulation}

ROSC occurred within 10 minutes of stopping CPR in 82\% of cases ( 23 out of 28 patients), with a mean delay of 7-8 minutes. The time taken for ROSC is unknown in 10 patients. Three of these patients were only found to be alive (one in the mortuary) after being left unattended for several minutes, and in seven the data was unavailable from the case reports. $2,5,9,12,18,28$ However, the time interval could only be an approximation because patients were not always closely monitored following termination of CPR, with a few exceptions. ${ }^{16}$

\section{Outcome}

Seventeen patients (45\%) achieved good neurological recovery following ROSC. Three of these patients subsequently died during their hospital stay due to sepsis and pulmonary embolism and 14 (35\%) were eventually discharged home with no significant neurological sequelae.

Seventeen patients (45\%) did not achieve neurological recovery following ROSC and died soon after. The outcome is not known in four patients $(10 \%)$. There was no significant correlation between the outcome and duration of $\mathrm{CPR}$, time interval for ROSC or the diagnosis. 


\begin{tabular}{|c|c|c|c|c|c|c|}
\hline Case number & Diagnoses & Duration of CPR & Rhythm & Time to ROSC & Functional Recovery & Ref \\
\hline 1 & $\mathrm{MI} / \mathrm{PE}$ & 10 & ASY & Mortuary & NO & 1 \\
\hline 2 & Ml & 10 & ASY & $<5 \min$ & NO & 1 \\
\hline 3 & $\mathrm{Ml}$ & 75 & ASY & 20 & YES & 1 \\
\hline 4 & $\mathrm{MI} / \mathrm{PO}$ & 20 & ASY & 5 & YES & 3 \\
\hline 5 & Trauma & 30 & ASY & 10 & YES & 4 \\
\hline 6 & Asthma & 25 & PEA & 3 & YES & 5 \\
\hline 7 & Addison's & 30 & ASY & 5 & YES & 6 \\
\hline 8 & NK & NK & ASY & NK & NO & 6 \\
\hline 9 & Stroke & 20 & ASY & 5 & NO & 6 \\
\hline 10 & NK & NK & ASY & NK & NO & 6 \\
\hline 11 & NK & NK & ASY & NK & NO & 6 \\
\hline 12 & Liver Res & NK & PEA & 15 & YES & 6 \\
\hline 13 & COPD & 20 & PEA & 15 & NO & 7 \\
\hline 14 & PA rupture & 23 & ASY & 5 & NO & 2 \\
\hline 15 & Asthma & 25 & PEA & Few min & NO & 8 \\
\hline 16 & $\mathrm{RF}$ & 26 & ASY & 8 & YES & 9 \\
\hline 17 & COPD & NK & PEA & NK & NK & 10 \\
\hline 18 & COPD & NK & PEA & NK & NK & 10 \\
\hline 19 & COPD & NK & PEA & NK & NK & 10 \\
\hline 20 & $\mathrm{RF}$ & 30 & ASY & 7 & NO & 11 \\
\hline 21 & $\mathrm{Ml}$ & 30 & VF & Few min & YES & 12 \\
\hline 22 & Anaemia & 35 & ASY & Few min & YES & 12 \\
\hline 23 & $\mathrm{MI}$ & 35 & NK & NK & NO & 13 \\
\hline 24 & $\mathrm{Ml}$ & 50 & PEA & Seconds & YES & 14 \\
\hline 25 & Stroke & 30 & ASY & 5 & NO & 15 \\
\hline 26 & MI & 35 & ASY & 13 & YES* & 16 \\
\hline 27 & COPD & 30 & ASY & 5 & NO & 17 \\
\hline 28 & $\mathrm{Ml}$ & 21 & PEA & 2 & YES & 18 \\
\hline 29 & MI/COPD & 15 & PEA & NK & NO & 19 \\
\hline 30 & AAA & 18 & ASY & 10 & YES & 20 \\
\hline 31 & Sepsis & 6 & NK & 5 & NK & 21 \\
\hline 32 & Drugs & 25 & ASY & 1 & YES & 22 \\
\hline 33 & $\mathrm{Ml}$ & 35 & PEA & 20 & NO & 23 \\
\hline 34 & AAA & 25 & ASY & 2 & YES & 24 \\
\hline 35 & Gl bleed & 40 & PEA & 2 & YES* & 25 \\
\hline 36 & $\mathrm{Ml}$ & 13 & ASY & Few min & NO & 26 \\
\hline 37 & D toxicity & 12 & ASY & 3 & YES* & 27 \\
\hline 38 & $\mathrm{Ml}$ & 25 & ASY & NK & $\mathrm{NO}$ & 28 \\
\hline
\end{tabular}

Abbreviations: AAA, Abdominal aortic aneurysm; ASY, Asystole; COPD, Chronic obstructive pulmonary disease; CPR, Cardiopulmonary resuscitation; D toxicity, Digoxin toxicity; Drugs, Recreational drug use; Gl bleed, Gastrointestinal bleeding; Liver Res, Liver resection; MI, Myocardial infarction; NK, Not known; PE, Pulmonary embolism; PEA, Pulseless electrical activity; PO, Pulmonary oedema; ROSC, Return of spontaneous circulation; VF, Ventricular fibrillation

${ }^{*}$ Functional recovery but died in hospital

\section{PROPOSED MECHANISMS}

The exact mechanism of delayed ROSC is unclear and it is possible that more than one mechanism is involved. Dynamic hyperinflation of the lung causing increased positive end expiratory pressure (PPEP) is one of the proposed mechanisms, which has some supporting evidence in patients with obstructive airways disease.

\section{Positive end expiratory pressure}

Rapid manual ventilation without adequate time for exhalation during CPR can lead to dynamic hyperinflation of lungs. Dynamic hyperinflation may lead to gas trapping and an increase in the end-expiratory pressure (called auto-PEEP) leading to delayed venous return, low cardiac output and even cardiac arrest in patients with obstructive airways disease. ${ }^{9}, 29,30$ 
The link between mechanical ventilation of patients with obstructive ventilatory defects and circulatory failure was first demonstrated in $1982 .{ }^{31}$ One report describes a patient with respiratory failure due to asthma whose blood pressure was undetectable five minutes after initiating artificial ventilation with a tidal volume of $700 \mathrm{~mL}$ and respiratory rate of 25 breaths per minute. Even after inotropes the systolic blood pressure did not exceed $70 \mathrm{~mm} \mathrm{Hg}$. The ventilator was adjusted to a respiratory rate of six breaths per minute and a tidal volume of $400 \mathrm{~mL}$ and the blood pressure gradually rose to $126 / 84 \mathrm{~mm} \mathrm{Hg} .^{29}$

The physiology of severe auto-PEEP is similar to pericardial tamponade, where circulation can only be restored after removing the obstacle to cardiac filling. AutoPEEP is a possible cause of pulseless electrical activity (PEA), and rapid ventilation during CPR should be avoided. Hypovolaemia and decreased myocardial contractility could exaggerate its effect on venous return and cardiac output. Some authors recommend discontinuing the ventilation transiently for 10 to 30 seconds in PEA to allow venous return. ${ }^{9}$

It is tempting to apply this theory even to patients without obstructive airways disease. Dynamic hyperinflation can theoretically happen in any situation where rapid manual ventilation is carried out. One could argue that in the presence of decreased cardiac output - as in myocardial infarction and hypovolaemia - dynamic hyperinflation could compromise the cardiac output even more, leading to cardiac arrest.

Even though auto-PEEP due to dynamic hyperinflation seems most plausible and has some evidence in patients with obstructive airways disease, this alone would not explain all cases of delayed ROSC. In one report, CPR was terminated after 30 minutes and the patient was in asystole. Because the patient had MRSA and CPR was performed without proper infection control measures, the physician involved in the CPR went to shower and change clothes, leaving the patient still being ventilated in the intensive care unit. Returning five minutes later, he found the patient with a perfusable rhythm. The patient died two days later. ${ }^{14}$

\section{Delayed action of drugs}

Some authors suggest delayed action of drugs administered during CPR as a mechanism for delayed $\operatorname{ROSC}^{8}$ It is possible that drugs injected through a peripheral vein are inadequately delivered centrally due to impaired venous return, and when venous return improves after stopping the dynamic hyperinflation, delivery of drugs could contribute to return of circulation. In some cases, however, drugs are actually administered through a central line. Even though this theory is plausible it would be impossible to either prove or disprove.

\section{Hyperkalaemia}

There are few reports of delayed ROSC in the presence of hyperkalaemia. ${ }^{8} 10$ It is a well-known fact that intracellular hyperkalaemia could persist longer, rendering the myocardium retractile for long periods of time. There is a report on a 68-year-old lady with cardiac arrest due to hyperkalaemia who did not respond to CPR and conventional treatment up to 100 minutes, but later responded to dialysis and made a complete recovery. ${ }^{32}$ So even though prolonged cardiac arrest refractory to conventional treatment could respond to dialysis, it is unlikely that hyperkalaemia on its own could explain delayed ROSC after cessation of CPR.

\section{Myocardial stunning}

Prolonged myocardial dysfunction can occur following myocardial ischaemia, taking up to several hours before normal function returns. ${ }^{33}$ Of the 38 cases, 13 had myocardial infarction, and at least seven had hypovolaemia which could have contributed to transient myocardial ischaemia and stunning.

\section{Transient asystole}

Asystole or PEA following countershock of prolonged VF is common and occurs in around $60 \%$ of patients. ${ }^{34}$ Even though restoration of circulation occurs in $16 \%$ of patients, the prognosis is poor: only $0-3 \%$ are discharged alive. It is possible that asystole or PEA after countershock could be transient before a perfusable rhythm restores circulation. Transient asystole following defibrillation would explain at least one case, where CPR was interrupted after a last cardioversion attempt resulting in asystole, and ROSC occurred soon after. ${ }^{11}$ However, transient asystole would not explain delayed ROSC in majority of patients in whom the duration of asystole was much longer. In another case, CPR was stopped while the patient was still in ventricular fibrillation and haemodynamic activity returned few moments later. ${ }^{11}$ The authors of the case rightly point out that CPR should not be halted in a patient with ventricular fibrillation.

\section{CONSEQUENCES OF DELAYED RETURN OF SPONTANEOUS CIRCULATION}

Delayed ROSC can lead to serious professional and legal consequences. Questions will be asked about whether CPR has been conducted properly and whether it was stopped too soon. The medical team might be accused of negligence and incompetence and even be sued for damages if a patient survives with severe disability. ${ }^{26,28,35} \mathrm{~A}$ doctor involved in resuscitation and certification of death followed by delayed ROSC has recently been accused of culpable homicide. 
The conduct of ALS can only be assessed from the case record, so it is vital to record the events during cardiac arrest as accurately as possible. When to discontinue CPR is still a medical decision and so it is absolutely essential to get a consensus from the arrest team and to document the reason for termination of CPR. Some authors recommend measurement of end-tidal carbon dioxide during CPR. Values above $10-15 \mathrm{mmHg}$ indicate a favourable prognosis and should preclude termination of CPR. ${ }^{36,37}$ This technology is not widely available outside the intensive care setting, but should be considered in difficult clinical situations. Whether this would identify patients in whom delayed ROSC might occur is nevertheless questionable.

\section{HOW WOULD ONE RECOGNIZE DEATH?}

It is important to realize that death is not an event, but a process. The conference of Medical Royal Colleges in the UK advocated that death is a process during which various organs supporting the continuation of life fail. ${ }^{38}$ Cessation of circulation and respiration is such an example. The physical findings to support this - absence of heartbeat and respiration - are the traditional and the most widely used criteria to certify death. Since these findings alone are not a sign of definitive death, it is quite possible to declare death in the interval between cessation of CPR and delayed ROSC.

Because delayed ROSC occurred within 10 minutes in most cases, many authors recommend that patients should be passively monitored for at least 10 minutes following unsuccessful CPR. During that period the family should be informed that CPR had been stopped because of poor response and further efforts are not in the best interests of the patient. It should also be mentioned that the patient is being closely monitored to establish death beyond any doubt. Death should not be certified in any patient immediately after stopping CPR, and one should wait at least 10 minutes, if not longer, to verify and confirm death beyond doubt. This is in line with what was said by $\mathrm{W} \mathrm{H}$ Sweet in 1978: 'the time honoured criteria of the stoppage of the heart beat and circulation are indicative of death only when they persist long enough for the brain to die.' 39

\section{NON-MEDICAL LITERATURE Newspapers}

In addition to medical literature, there are many newspaper articles, websites and a few anecdotes in medical journals describing patients who were certified dead, but later found to be alive (Table 2). Many of these articles refer to these

\section{Table 2 Media reports}

\section{Newspaper articles}

1 Stockwell J. Paramedics Mistakenly Thought VA Woman Dead. The Washington Post 19 March 2005.

2 The Associated press. Misdiagnosis of Death Shocks Rural Town. The New York Times 13 February 2005.

3 Chandigarh, India. 'Dead' Man Disappears from Hospital. The Tribune Haryana 19 January 2004,

4 CNN. 'Body' in Morgue Freezer Was Alive. archives.cnn.com/2002/WORLD/Europe/08/12/france.dead./index.html 12 August 2002

5 Misslebeck WJA. The Lazarus Phenomenon. Vermont EMS Today March 2001

6 BBC. Old Man Alive In Mortuary Fridge. news.bbc.co.uk/1/hi/world/asia-pacific/1078350.stm 19 December 2000

7 Jauhar S. Cases; Journeys From Death To Life. The New York Times 12 December 2000

\section{Medical journals}

$1 \quad$ Dalrymple T. Not dead yet—and buried. British Medical Journal 2007; 334: 99

2 Poulter NR. Uses of error: suppositions and surprises. Lancet 2001; 358: 1448

3 Reilly BM. Pronouncing, on being a doctor. Annals of Internal Medicine 2001; 135: 467-70

\section{Websites}

1 The Lazarus Phenomenon (DVD). www.paxkom.co.uk/lazarus-phenomenon-more.htm

2 Just Dying to Get Out: People Have Been Buried Alive by Mistake. www.snopes.com/horrors/gruesome/buried.asp

3 Jarvis G. Robert E. Lee's Mother. http://www.lewrockwell.com/jarvis/jarvis81.html

4 Bonnke R. The rich mans prayer is answered. http://www.letusreason.org/Popteac13.htm

5 Lazarus Phenomenon Medical information. http://www.thehousecall.com/LazarusPhenomenon.html 
incidents as 'Lazarus phenomenon'. There is even a movie called Lazarus phenomenon describing two cases of resurrection after death. However, the authenticity of one of these cases has been questioned.

\section{Websites}

A website (www.snopes.com/horrors/gruesome/buried.asp) describing people who have been buried alive by mistake in the last few centuries provides entertaining reading. In olden days a number of illnesses could cause coma and there was a danger of hasty disposal of the body especially in those with infectious diseases.

\section{Literature}

Edgar Allan Poe's most hair-raising tale is The Premature Burial, in which a young wife was incorrectly pronounced dead and kept in a coffin in the family vault. When the vault was opened a few years later to receive another coffin, a shrouded skeleton was found in the doorway suggested that the lady had survived and eventually died unable to open the vault door. It is believed that he based his story on a widely reported incident that took place around that time. ${ }^{40}$

It seems that the chances of being buried alive were not so remote in $1800 \mathrm{~s}$. The fear of being buried alive was so prevalent that many people specified in their wills that tests must be carried out to confirm their death, such as pouring hot liquids on the skin, touching the skin with red-hot irons, or making surgical incisions prior to the burial. A coffin was invented and patented in 1897 to allow a person accidentally buried alive to summon help through a system of flags and bells. The fear of being buried alive is called 'taphophobia' in the medical literature. There was even a Society for the Prevention of Burial Before Death, which recognized the difficulties in diagnosing death and issued educational leaflets to assist members of the society.

\section{LAZARUS IN OTHER CONTEXTS}

The term Lazarus has also been used to describe many other unexpected and scientifically unexplainable phenomena. Lazarus complex describes the psychological sequence in the survivors of cardiac arrest, near-death experiences and unexpected remission in AIDS. ${ }^{41,42}$ Lazarus syndrome is described in paediatric palliative care, when a child is expected to die but unexpectedly goes into remission. ${ }^{35}$ Spontaneous movement in brain dead and spinal cord injury patients has been described as Lazarus sign. ${ }^{43,44}$ Survival of species after mass extinction has been called Lazarus effect. ${ }^{45}$ The term Lazarus phenomenon was also used for unexpected survival of renal graft patients. ${ }^{46}$

Lazarus premonition describes an unexpected state of brief resurrection in terminally ill patients, when they experience an increase in vitality, appetite and general improvement. ${ }^{47,48}$ This was recognized at least a thousand years ago in the medieval Chinese literature and was described as hui guang fan zhao, meaning reflected rays of setting sun. Recently a 'Lazarus Pill' (Zolpidem, a nonbenzodiazepine sedative) has aroused medical interest in patients with persistent vegetative state. This was following a report where a patient with persistent vegetative state showed a brief remarkable neurological response to zolpidem. ${ }^{49}$

\section{RESURRECTION}

There are many other resurrections in addition to that of Lazarus. Three resurrections are recorded in the Old Testament, one each by Elijah, Elisha and Elisha's bones. There are many resurrections in the New Testament, four by Jesus (including Lazarus) and one each by Paul and Peter. ${ }^{50}$ In Hindu mythology Sathyavan's wife Savithri convinces the Lord of death (Yamaraj) to resurrect Sathyavan following his death after being caught under a falling tree. These stories illustrate that humanity's preoccupation with death and resurrection is universal. The greatest example of Lazarus phenomenon is probably the death and resurrection of Jesus Christ himself.

\section{KEY POINTS}

- Lazarus phenomenon is described as delayed ROSC after cessation of CPR;

- Dynamic hyperinflation should be considered as a reversible of cause of PEA;

- Patients should be observed for at least 10 minutes using blood pressure and ECG monitoring after the cessation of CPR before confirming death.

Competing interests None declared.

Guarantor VA.

Contributorship All authors contributed equally.

\section{REFERENCES}

1 Bray JG. The Lazarus phenomenon revisited. Anesthesiology 1993;78: 991

2 Linko K, Honkavaara P, Salmenpera M. Recovery after discontinued cardiopulmonary resuscitation. Lancet 1982;1:106-7

3 Letellier N, Coulomb F, Lebec C, Brunnet JM. Recovery after discontinued cardiopulmonary resuscitation. Lancet 1982;1:1019

4 Klockgether A, Kontokollias JS, Geist J, Schoenneich A. Monitoring im Rettungsdienst. Notarzt 1987;3:85-8

5 Rosengarten PL, Tuxen DV, Dziukas L, Scheinkestel C, Merret K, Bowes G. Circulatory arrest induced by intermittent positive pressure ventilation in a patient with severe asthma. Anaesth Intensive Care 1991; 19:118-21 
6 Skulberg A. Criteria of death and time of death-do Norwegian physicians follow laws and regulations? [Norwegian]. Tidsskr Nor Lageforen 1991;111:3310-1

7 Rogers PL, Schlichtig R, Miro A, Pinsky M. Auto-PEEP during CPR: an 'occult' cause of electromechanical dissociation? Chest 1991;99:492-3

8 Martens P, Vandekerckhove Y, Mullie A. Restoration of spontaneous circulation after cessation of cardiopulmonary resuscitation. Lancet 1993;341:841

9 Quick G, Bastani B. Prolonged asystolic hyperkalemic cardiac arrest with no neurological sequelae. Ann Emerg Med 1994;24:305-11

10 Lapinsky SE, Leung RS. Auto-PEEP and electromechanical dissociation. NEJM 1996;335:674

11 Voelckel W, Kroesen G. Unexpected return of cardiac action after termination of cardiopulmonary resuscitation. Resuscitation 1996;32: 27-9

12 Gomes E, Araujo R, Abrunhosa R, Rodrigues G. Two successful cases of spontaneous recovery after cessation of CPR. Resuscitation 1996;31: 40

13 Mutzbauer TS, Stahl W, Lindner KH. Compression-Decompression (ACD)-CPR. Prehosp Disaster Med 1997;12:S21

14 Fumeaux T, Borgeat A, Cuénoud PF, Erard A, de Werra P. Survival after cardiac arrest and severe acidosis $(\mathrm{pH}$ 6.54). Intensive Care Med 1997;23:594

15 Maleck WH, Piper SN, Triem J, Boldt J, Zittel FU. Unexpected return of spontaneous circulation after cessation of resuscitation (Lazarus phenomenon). Resuscitation 1998;39:125-8

16 Frölich MA. Spontaneous recovery after discontinuation of intraoperative cardiopulmonary resuscitation. Anesthesiology 1998;89: 1252-3

17 MacGillivray RG. Spontaneous recovery after discontinuation of cardiopulmonary resuscitation. Anesthesiology 1999;91:585-6

18 Bradbury N. Lazarus phenomenon: another case? Resuscitation 1999; 41:87

19 Adhiyaman V, Sundaram R. The Lazarus phenomenon. J R Coll Phys Edin 2002;32:9-13

20 Ben-David B, Stonebraker VC, Hersham R, Frost CL, Williams HK. Survival after failed intraoperative resuscitation: a case of 'Lazarus Syndrome'. Anesth Analg 2001;92:690-2

21 Abdullah RS. Restoration of circulation after cessation of positive pressure ventilation in a case of 'Lazarus Syndrome'. Anesth Analg 2001;93:241

22 Walker A, McClelland H, Brenchley. Lazarus phenomenon following recreational drug use. Emerg Med J 2001;18:74-5

23 Maeda H, Fujita MQ, Zhu BL, et al. Death following spontaneous recovery from cardiopulmonary arrest in a hospital mortuary: 'Lazarus phenomenon' in a case of alleged medical negligence. Forensic Sci Int 2002;127:82-7

24 Dück MH, Paul M, Wixforth J, Kämmerer H. The Lazarus phenomenon. Spontaneous return of circulation after unsuccessful intraoperative resuscitation in a patient with a pacemaker (German). Anaesthesist 2003;52:413-8

25 Casielles Garcia JL, Gonzalez Latorre MV, Fernadez Amigo N, et al. Lazarus phenomenon: spontaneous resuscitation (Spanish). Rev Esp Anestesiol Reanim 2004;51:390-4

26 De Salvia A, Guardo A, Orrico M, De Leo D. A new case of Lazarus phenomenon? Forensic Sci Int 2004;146:S13-5
27 Al-Ansari MA, Abouchaleh NM, Hijazi MH. Return of spontaneous circulation after cessation of cardiopulmonary resuscitation in a case of digoxin overdosage. Clinical Intensive care 2005;16:179-81

28 Monticelli F, Bauer N, Meyer HJ. Lazarus phenomenon. Current resuscitation standards and questions for the expert witness (German). Rechtmedizin 2006;16:57-63

29 Wiener C. Ventilatory management of respiratory failure in asthma. JAMA 1993;269:2128-31

30 Sprung J, Hunter K, Barnas GM, Bourke DL. Abdominal distension is not always a sign of esophageal intubation: Cardiac arrest due to 'AutoPEEP'. Anesth Analg 1994;78:801-4

31 Pepe PE, Marini JJ. Occult positive end-expiratory pressure in mechanically ventilated patients with airflow obstruction: the autoPEEP effect. Am Rev Respir Dis 1982;126:166-70

32 Kao KC, Huang CC, Tsai YH, Lin MC, Tsao TC. Hyperkalemic cardiac arrest successfully reversed by hemodialysis during cardiopulmonary resuscitation: case report. Chang Gung Med J 2000; 23:555-9

33 Braunwald E, Kloner RA. The stunned myocardium: prolonged, postischemic ventricular dysfunction. Circulation 1982;66:1146-9

34 Niemann JT, Stratton SJ, Cruz B, Lewis RJ. Outcome of out-ofhospital postcountershock asystole and pulseless electrical activity versus primary asystole and pulseless electrical activity. Crit Care Med 2001;29:2366-70

35 Lantos JD. The Lazarus Case: Life and Death Issues in Neonatal Intensive Care. Baltimore: Johns Hopkins University Press, 2001

36 Ward KR, Yealy DM. End-tidal carbon dioxide monitoring in emergency medicine, part 2: Clinical applications. Acad Emerg Med $1998 ; 5: 637-46$

37 Maleck WH, Piper SN. Recovery after discontinuation of cardiopulmonary resuscitation ('Lazarus phenomenon'). Anesthesiology 1999;2:584-5

38 Conference of Medical Royal Colleges and their Faculties in the United Kingdom 1979. Diagnosis of death. BMJ 1979;1:332

39 Sweet WH. Brain death. NEJM 1978;299:410-2

40 http://www.lewrockwell.com/jarvis/jarvis81.html

41 Hackett TP. The Lazarus complex revisited. Ann Intern Med 1972;76: $135-7$

42 Gregonis SW. Magic Johnson and Lazarus: the new syndromes. J Assoc Nurses AIDS Care 1997;8:75-6

43 Ropper AH. Unusual spontaneous movements in brain-dead patients. Neurology 1984;34:1089-92

44 Mandel S, Arenas A, Scasta D. Spinal automatism in cerebral death. NEJM 1982;307: 501

45 Jablonski D. Causes and consequences of mass extinctions: a comparative approach. In: Elliot DK, ed. Dynamics of Extinction. New York: Wiley, 1986:183-229

46 Gambosa E, Bronsther O, Halasz N. The Lazarus phenomenon. Clin Transplant 1986;1:125

47 Witzel L. Behaviour of the dying patient. BMJ 1975;2:81-2

48 JKT Ngeh. Observations of the phenomenon of hui guang fan zhaoLazarus premonition (Filler). Age Ageing 2002;31:434

49 Williams J. In whose interests? BMA News 2007; 10 February: 14

50 www.bibleufo.com/gentech6.htm 